\title{
Genome-wide identification, characterization and expression analysis of MATE family genes in apple (Malus $X$ domestica Borkh)
}

\author{
Weihan Zhang ${ }^{1+}$, Liao Liao ${ }^{2+}$, Jinsheng $\mathrm{Xu}^{1}$, Yuepeng $\operatorname{Han}^{2}$ and $\mathrm{Li} \mathrm{Li}^{1,3^{*}}$
}

\begin{abstract}
Background: As an important group of the multidrug efflux transporter family, the multidrug and toxic compound extrusion (MATE) family has a wide range of functions and is distributed in all kingdoms of living organisms. However, only two MATE genes in apple have been analyzed and genome-wide comprehensive analysis of MATE family is needed.

Results: In this study, a total of 66 MATE (MdMATE) candidates encoding putative MATE transporters were identified in the apple genome. These MdMATE genes were classified into four groups by phylogenetic analysis with MATE genes in Arabidopsis. Synteny analysis reveals that whole genome duplication (WGD) and segmental duplication events played a major role in the expansion of MATE gene family in apple. MdMATE genes show diverse expression patterns in different tissues/organs and developmental stages. Analysis of cis-regulatory elements in MdMATE promoter regions indicates that the function of MdMATE genes is mainly related to stress response. Besides, the changes of gene expression levels upon different pathogen infections reveal that MdMATE genes are involved in biotic stress response.

Conclusions: In this work, we systematically identified MdMATE genes in apple genome using a set of bioinformatics approaches. Our comprehensive analysis provided valuable resources for improving disease resistance in apple and further functional characterization of MATE genes in other species.
\end{abstract}

Keywords: Apple, MATE, Gene family, Expression profile, Disease resistance

\section{Background}

The multidrug and toxic compound extrusion (MATE) protein belongs to a multidrug efflux transporter family, which plays a role in transporting multiple kinds of substrates, such as secondary metabolites and

\footnotetext{
* Correspondence: li.li@mail.hzau.edu.cn

${ }^{+}$Weihan Zhang and Liao Liao contributed equally to this work.

'Hubei Key Laboratory of Agricultural Bioinformatics, College of Informatics, Huazhong Agricultural University, Wuhan 430070, People's Republic of China ${ }^{3}$ Hubei Hongshan Laboratory, Huazhong Agricultural University, Wuhan 430070, People's Republic of China

Full list of author information is available at the end of the article
}

phytohormones [1]. The process of detoxification mainly involves four transporter families: ATP-binding cassette superfamily $(\mathrm{ABC})$, resistance/nodulation/division family (RND), small gene multidrug resistance family (SMR), and major facilitator superfamily (MFS) [2]. Members of the $\mathrm{ABC}$ superfamily are considered to be primary transporters, and ATP provides energy during transport [3]. The transmembrane transport of primary transporters is mainly carried out by releasing energy [4]. The members of RND, SMR and MFS are secondary transporters and mainly use the electrochemical penetration potential

C C The Author(s). 2021 Open Access This article is licensed under a Creative Commons Attribution 4.0 International License, which permits use, sharing, adaptation, distribution and reproduction in any medium or format, as long as you give appropriate credit to the original author(s) and the source, provide a link to the Creative Commons licence, and indicate if changes were made. The images or other third party material in this article are included in the article's Creative Commons licence, unless indicated otherwise in a credit line to the material. If material is not included in the article's Creative Commons licence and your intended use is not permitted by statutory regulation or exceeds the permitted use, you will need to obtain permission directly from the copyright holder. To view a copy of this licence, visit http://creativecommons.org/licenses/by/4.0/ The Creative Commons Public Domain Dedication waiver (http://creativecommons.org/publicdomain/zero/1.0/) applies to the data made available in this article, unless otherwise stated in a credit line to the data. 
caused by the difference between the internal and external material concentration of the membrane to implement transport process [4]. In these secondary transporter families, numerous MFS family members with different functions are widely distributed in both higher and lower organisms. Most MFS superfamily members contained 12 membrane alpha-helix and use cations $\left(\mathrm{H}^{+}\right.$or $\mathrm{Na}^{+}$ions) electrochemical gradients to drive substrate export [5, 6]. In 1998, a new multidrug efflux system named NorM that can increase the efflux of norfloxacin in the absence of a multidrug efflux system in the host was found in E. coli. Meanwhile, a high sequence homology multidrug efflux protein was also found and named YdhE [7]. Although the structure of NorM is similar to the MFS superfamily that has 12 transmembrane regions (TMs), both NorM and YdhE proteins have no homology with members of the MFS superfamily, nor a specific signal sequence for this family [8]. Therefore, the new secondary transporter family, NorM and YdhE, become the fifth kind of transporter family which is named as multidrug and toxic compound extrusion (MATE) [9].

Previous study has shown that MATE transporters are widely distributed in all kingdoms of living organisms [1]. The protein length of most MATE transporters is 400-700 amino acids, containing 8-12 transmembrane domains $[10,11]$. The first plant MATE transporter was identified in Arabidopsis named A. thaliana aberrant lateral root formation 5 (AtALF5), which is associated with roots epidermal cells development and toxic compounds export [12]. In recent years, several studies have been conducted to characterize the function of MATE proteins in the model organism Arabidopsis and have shown that MATE proteins have various functions. For example, the TRANSPARENT TESTA 12 (TT12) encodes a MATE transporter which can mediate anthocyanin transport [13] and the AtDTX1 (DETOXIFICATION 1 ) is the first multi-specific MATE transporter control the export of toxic compounds from the cytoplasm [10]. In contrast to the mammal, plant genomes carry a larger number of MATE genes [14]. For instance, 56 in Arabidopsis [10], 48 in potato [6], 49 in maize [15], 45 in rice [16] and 117 in soybean [17]. Extensive research on MATE gene family suggest diverse functions, which are involved in stress responses, secondary metabolite and phytohormone transport, plant growth and development $[18,19]$. However, the function and status of MATE gene family in fruit trees have rarely been reported.

Apple (Malus $\times$ domestica Borkh.) is one of the most economically important and popular perennial fruit crops in temperate regions. It is highly susceptible to infection by pathogen and greatly affect quality and yield. The development of resistance in pathogens and the large investment of farmers in fungicides have become an important issue [20]. A previous study showed that the expression levels of MATE gene family are involved in pathogen susceptibility [21]. However, as far as we know only two MATE genes (MdMATE1 and $M d M A T E 2)$ in apple were analyzed, which are homologs of TT12 in Arabidopsis and participate in proanthocyanidins accumulating in cells and flavonoid transport [22]. A comprehensive analysis of the MATE gene family is needed in the apple genome.

In this study, we identified 66 MATE genes (MdMATE) in apple genome and conducted comprehensive analysis regarding their phylogenetic relationship, synteny, gene structure, evolution, expression in different tissues/organs and developmental stages, and cis-elements. Synteny analysis shows that WGD/segmental duplication events played a major role in the expansion of MATE gene family in apple. Expression analysis suggests that MdMATE genes have specific expression patterns in different tissues/organs and developmental stages. Correlation analysis reveals that the functions of duplicated gene pairs may have divergence. We also found that MdMATE genes are involved in biotic stress response. Our study provides clues for further functional studies of MATE genes in plants and improvement of disease resistance in apple.

\section{Results}

Genome-wide identification of MATE transporters in apple

A total of 66 genes encoding MATE transporters were identified in the apple reference genome GDDH13 version 1.1 [23] after homologous sequence alignment with AtMATE genes from A. thaliana and manual filtering (see Methods) (Additional file 1: Table S1). Since two MATE transporters, MdMATE1 and MdMATE2, have been reported in previous study [22], we renamed the other 64 transporters as MdMATE3 - MdMATE66 based on their physical locations (Additional file 1: Table S2).

The basic properties including the length of protein sequence, theoretical isoelectric point (pI), molecular weight $(\mathrm{MW})$ and subcellular localization were analyzed to further characterize the MdMATE proteins (Additional file 1: Table S2). The 66 MdMATE proteins consist of 406 to 712 amino acids in length, which is quite similar to MATE proteins in Arabidopsis (400-700 amino acids) [10], but different from soybean (80-593 amino acids) [17], Populus (120-608 amino acids) [24] and rice (469-575 amino acids) [16]. The MW and pI ranges from 45.20 to $77.02 \mathrm{kDA}$ and 5.05 to 9.54 , respectively. Subcellular location prediction results include plasma membrane (56), chloroplast (5), cytoplasm (2), vacuole (2), and endoplasmic reticulum (1). 
Phylogenetic, gene structures and motif composition analysis of the MATE family in apple

Using the full-length protein sequences of the 122 MATE transporters, including 56 from Arabidopsis and 66 identified in apple, we constructed a maximum likelihood (ML) phylogenetic tree (Fig. 1). The 66 MdMATE transporters were divided into four groups (I, II, III and IV), which is in accordance with what was reported for MATE transports in Arabidopsis [10]. A neighborjoining (NJ) tree was also constructed to validate the phylogenetic relationship and show a similar grouping mode as ML tree (Additional file 2: Fig. S1). The group sizes vary from 9 to 23. Group I, II, III and IV contain 14, 20, 9 and 23 MdMATE transporters, respectively. We further aligned MdMATE transporters to construct an individual phylogenetic tree by the same method and parameters and got consistent clustering patterns (Fig. 2A).

To gain more insight into the diversity of the MATE family in apple, we examined the exon-intron organization of all the identified MdMATE genes (Fig. 2B). The MdMATE genes display one to fifteen exons (5 with one exon, 7 with two exons, 2 with three exons, one with five exons, 5 with six exons, 24 with seven exons, 11 with eight exons, and 11 with nine or more exons). The length of exons ranging from 9 (MdMATE3) to 1680 (MdMATE6) bp. The fewest number of exons are observed in MdMATE6, MdMATE25, MdMATE14, MdMATE10, and MdMATE66. These five genes all have only one exon and clustered in group IV. Additionally, 9 genes have more than thirteen exons. Overall, MATE gene family in apple showed complex gene structures with varying exons and lengths.

Motifs of the 66 MdMATE proteins were identified by MEME [25] to analyze the function and/or structural roles of highly conserved amino acid residues in active proteins [26]. A total of 12 conserved motifs, designated as motif 1 to motif 12, were identified (Fig. $2 \mathrm{C}$ and Additional file 2: Fig. S2). Most MdMATE proteins have similar motifs within the same group. Of these, motif 12 was found in all the MdMATE proteins except for MdMATE66. Interestingly, in group IV, some MdMATE proteins have fewer motifs $(\leq 3)$, but more exons $(\geq 13)$ than other genes. Based on the structure and motif differences in group IV, the group IV we further divided into two subgroups: Group IV-a and Group IV-b (Fig.

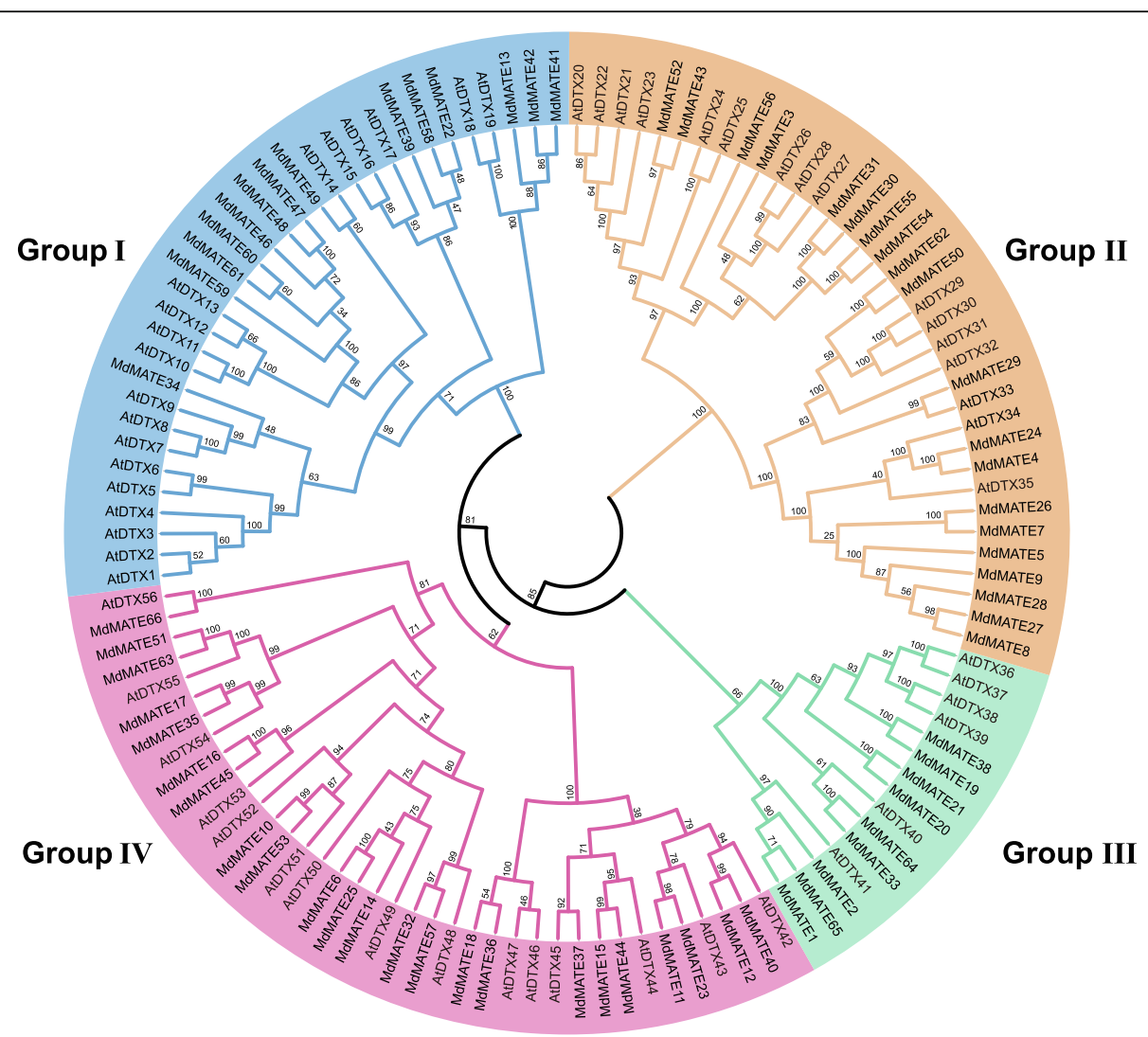

Fig. 1 The unrooted maximum likelihood phylogenetic tree of MATE family members in apple and Arabidopsis. The different colors indicate different groups (Group I in blue, Group II in orange, Group III in green and Group IV in pink). 'MdMATE' represents MATE members from apple, 'AtDTX' represents MATE members from Arabidopsis. Numbers on the nodes are bootstrap values in percentage (1000 replicates) 

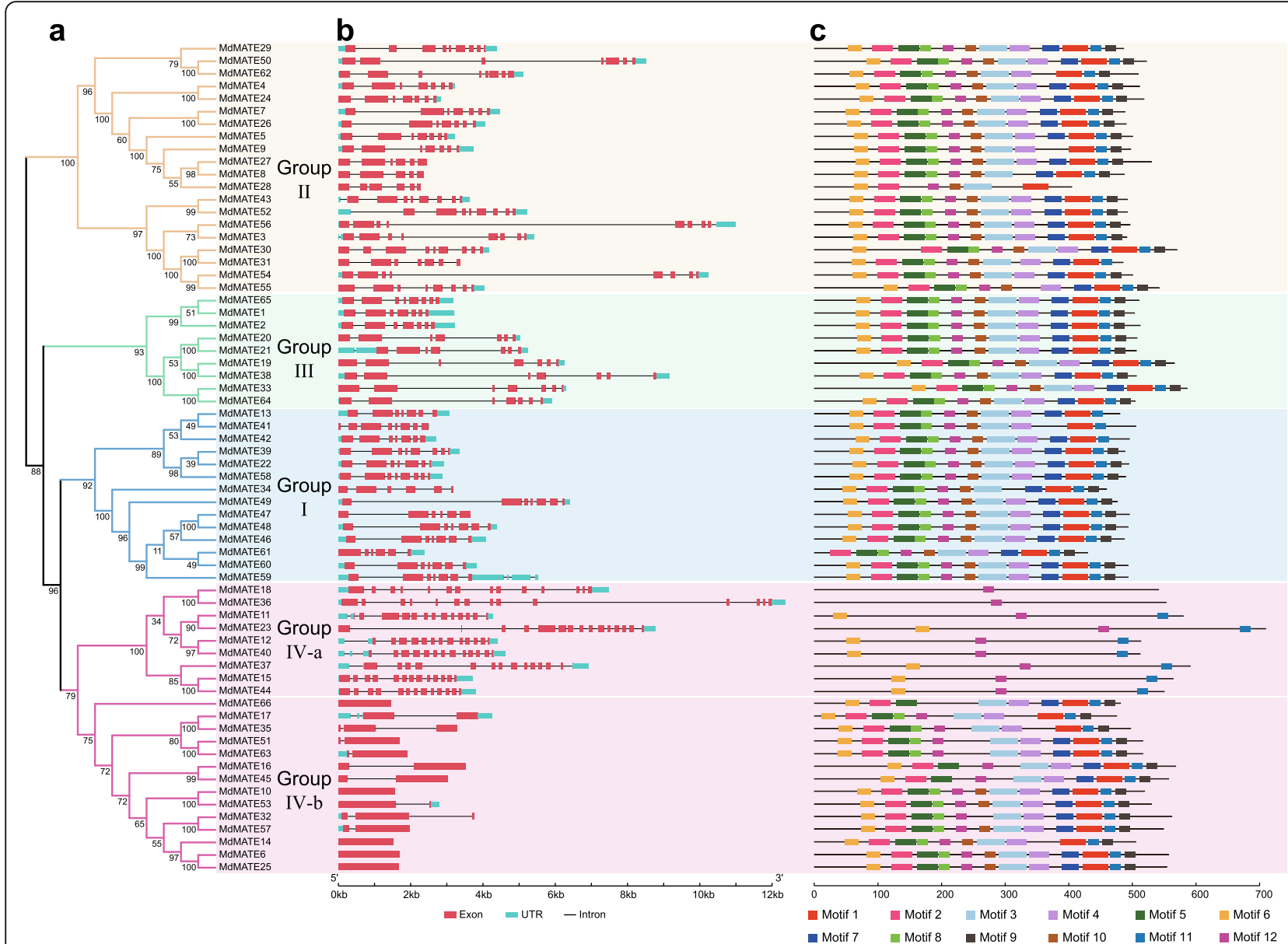

Fig. 2 Phylogenetic relationships and structures of 66 MdMATE genes. A. A Phylogenetic tree inferred from full length sequence of MdMATE genes. The number on the nodes are bootstrap value in percentage (1000 replicates). Color of branches represents different groups same with the phylogenetic tree in Fig. 1 (Group I in blue, Group II in orange, Group III in green and Group IV in pink). B. Exon-intron structure of MdMATE genes. The boxes represent exons or UTRs, lines represent introns. C. Motif composition of MdMATE proteins. Different color boxes indicate different motifs. The length of genes or proteins can be estimated using the scale at the bottom

2A). The group IV-a with more exons but fewer motifs, while the group IV-b is in contrast. These observations are consistent with studies of MATE gene family in other species such as soybean [17], cotton [27] and flax [28].

\section{Chromosomal location and evolution of apple MATE transporters}

The distribution of MdMATE genes is uneven on the 17 chromosomes of apple genome $(2 \mathrm{n}=34) \quad$ (Fig. 3). Chromosome 1 contains the highest number of MdMATE genes (7), whereas both chromosomes 6 and 14 contain only one gene. There is no significant correlation between chromosome length and MdMATE gene number (Spearman's $\rho=0.317, P=0.2157$ ). Additionally, majority of these MdMATE genes are located on the chromosome arms, which are the regions with relative high recombination rate [29].
Gene duplications are considered to be one of the major driving forces in the evolution of genomes and expansions of the gene families [30, 31]. Whole genome duplication, segmental duplication and tandem duplication are the major causes of gene family expansion in plants [32]. We detected the duplicated events for MdMATE genes by MCscanX [33]. As shown in Fi gure 3 , 26 gene pairs with $39(59 \%)$ genes were identified as WGD/segmental duplication, while 20 (30\%) tandem duplicated genes were identified within 7 tandem duplicated gene clusters (Additional file 1: Table S3). These results indicate that MATE family in apple expands mainly by gene duplications, with WGD/segmental duplication as the driving force.

\section{Synteny analysis of MATE family in green plants}

As an integral membrane protein involved in a diverse array of functions, MATE family of transporters are abundant in plants [11]. We constructed four 


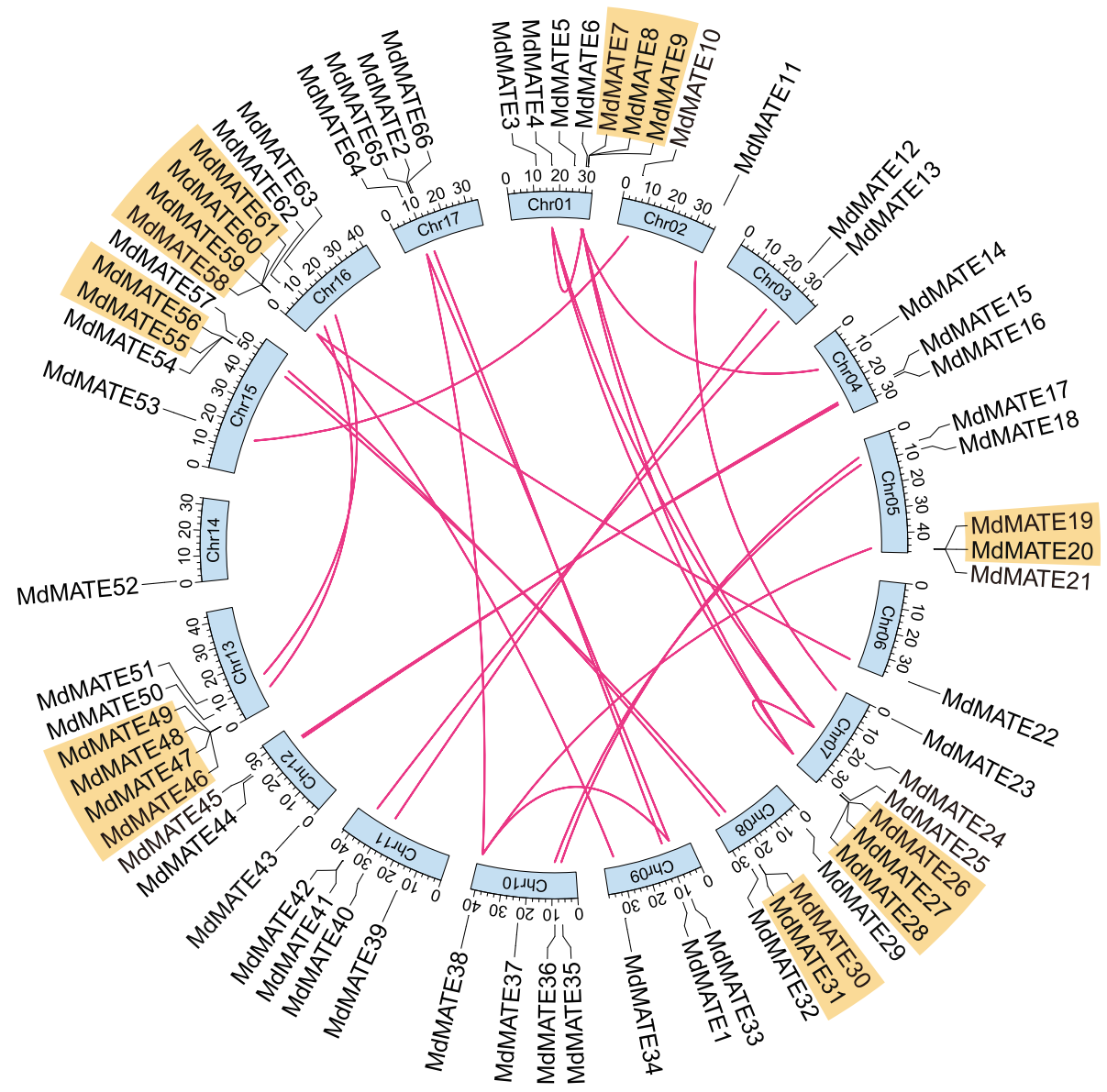

Fig. 3 Chromosome distribution and collinear relations of MdMATE genes. The scale on the circle is in Mega bases. Gene IDs on the chromosomes indicate their physical positions. Red lines indicate segmental duplicated MdMATE gene pairs. Orange regions indicate tandem clusters

comparative syntenic maps of apple associated with four representative green plants to further investigate the phylogenetic mechanisms of MATE gene family in apple, including two dicots (Arabidopsis and soybean) and two monocots (maize and rice) (Fig. 4A). Among MdMATE genes, $68.2 \%$ (45 of 66 genes) were found associated with at least one collinear gene pair (Fig. 4B). A total of 42 MdMATE genes showed collinear relationship with 56 GmMATE genes in soybean, while 32 MdMATE genes showed collinear relationship with 26 AtDTX genes in Arabidopsis. In monocots, however, only 13 and 8 MdMATE genes collinear with 12 MATE genes in rice and 8 MATE genes in maize, respectively (Fig. $4 \mathrm{C}$ and Additional file 1: Table S4). Thus, the MdMATE genes show more collinear gene pairing with dicots than monocots.

For the collinear gene pairs between apple and soybean, which shows the most collinear relationships, 31 MdMATE genes are associated with two or more GmMATE genes. The MdMATE14, with 8 collinear GmMATE genes, is the gene with the most collinear relationships. In contrast, for Arabidopsis, most MdMATE genes associated with one or two AtDTX genes. Only MdMATE38 associated three AtDTX genes. This might result from two whole genome duplication events in soybean [34]. Interestingly, 30.3\% (20 of 66 genes) of MdMATE genes have collinear gene pairs in both Arabidopsis and soybean, but no collinear gene pairs in monocots (Fig. 4B). For example, MdMATE1 collinear with AtDTX41 and GmMATE81, but shows no collinear gene in maize or rice. This is similar with observation of WRKY family in pineapple in the sense that these MATE orthologous gene pairs appear after the divergence of dicotyledonous and monocotyledonous plants [31]. Notably, three MdMATE genes, MdMATE14, MdMATE19, and MdMATE38, have collinear relationships between apple and all of the other four species, indicating that these orthologous pairs are conserved and may already exist before the ancestral divergence. These collinear gene pairs between apple and other species may be valuable for elucidating the evolution of MATE genes in green plants. 

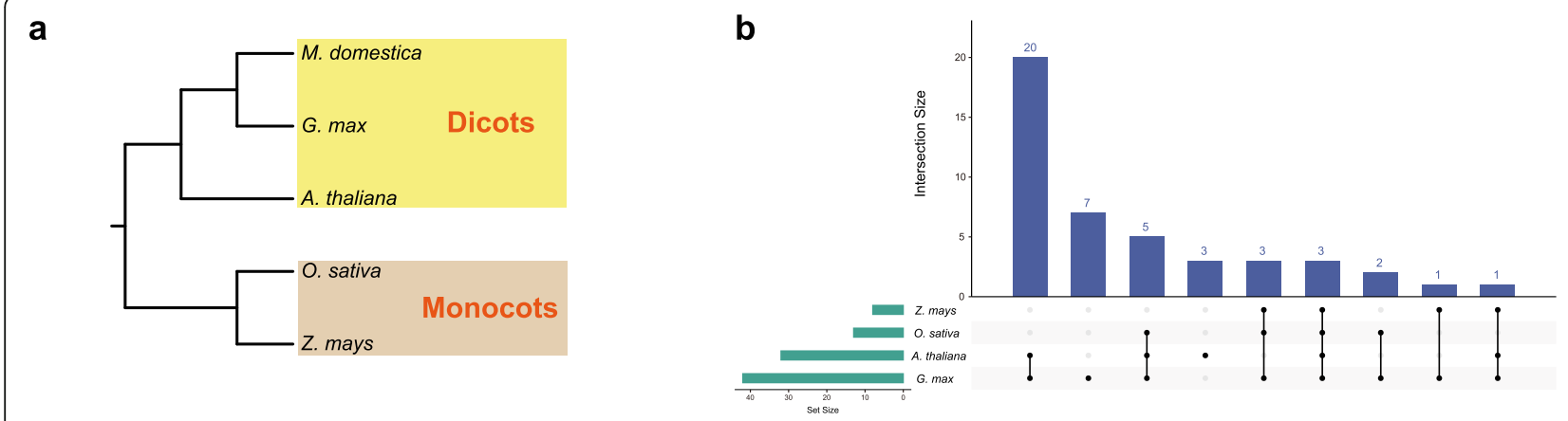

C
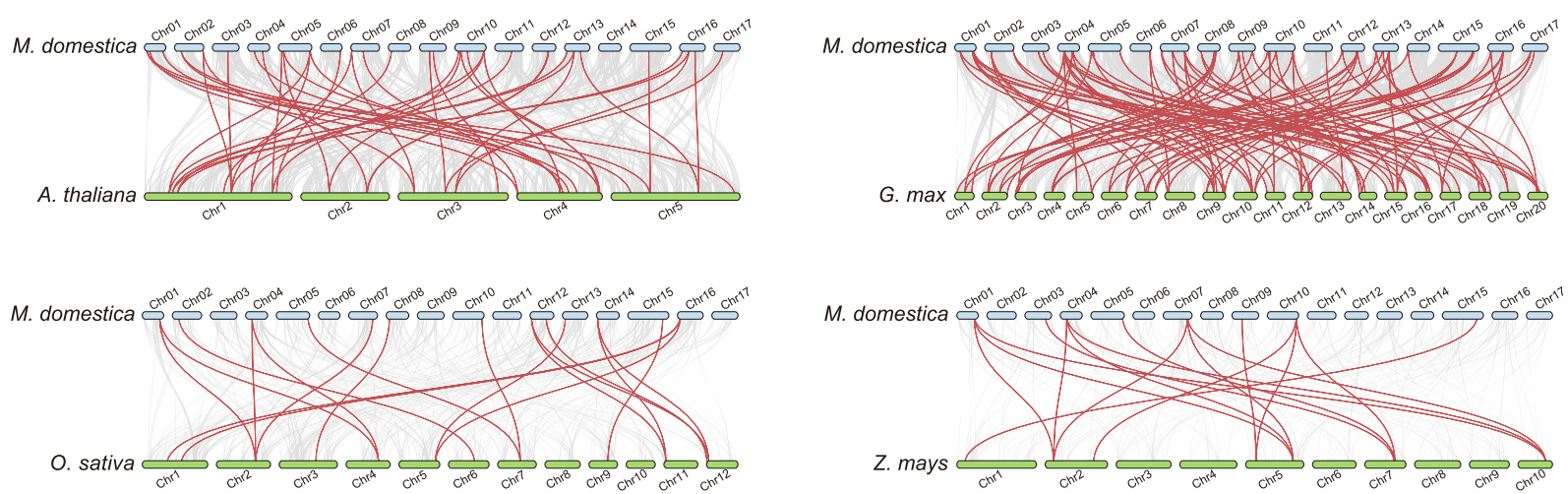

Fig. 4 Synteny relationships of MdMATE genes with other four plant species. A. Species tree of apple and other four species. B. UpSet plot of collinear MATE genes between apple and other four species. Each vertical bar (dark blue) shows the number of MdMATE genes collinear with other species by the intersection matrix below it (a single dot in the matrix is a single species, 2 dots $=2$ species, etc.). The number of genes in each species found to have collinear relationships with atleast one MdMATE genes is indicated by the horizontal bar (green) extending to the left. C. Synteny analysis of MATE genes between apple and other species. The red lines indicate the syntenic MATE gene pairs, while the gray lines in the background indicate the collinear blocks within apple and other plant genomes. The specie names with the prefixes ' $M$. domestica', 'A. thaliana', 'G. max', 'O. sativa' and 'Z. mays' indicate Malus $x$ domestica Borkh., A. thaliana, G. max, O. sativa and Z. mays, respectively

To better understand the different selective constraints on MATE gene family, the $\mathrm{Ka} / \mathrm{Ks}$ ratios of the MATE gene pairs within apple and between apple and the other four plants were calculated (Additional file 1: Table S4). All segmental and tandem duplicated MdMATE gene pairs and the orthologous MATE gene pairs had $\mathrm{Ka} / \mathrm{Ks}<$ 1 , suggesting that the MATE gene family in apple have experienced strong purifying selective pressure during the evolution.

\section{Expression patterns of MdMATE genes in different apple tissues/organs and developmental stages}

To dissect the expression patterns of MdMATE genes in various tissues/organs and developmental stages, a total of 36 expression profiles of $66 \mathrm{MdMATE}$ genes were obtained from Apple Multi-Dimensional Omics Database (AppleMDO) [35] (Fig. 5A and Additional file 1: Table S5). The MdMATE genes with Fragments Per Kilobase per Million (FPKM) values less than 1 in all 36 expression profiles are considered to be barely expressed [4]. Thus, 11 genes are not expressed in all 36 tissues/organs and developmental stage profiles. The remaining 55 genes are expressed in at least one profile. Among them, MdMATE1 is expressed in all developmental stages of fruit flesh and peel, while MdMATE2 shows expression level declining from earlier to later developmental stages. This is consistent to the real-time RT-PCR results published by previously study [22].

Among the 55 expressed genes, MdMATE7 and MdMATE36 showed constitutive expression (FPKM $>1$ in all tissues/organs and developmental stages). It suggests that these two genes may involve apple growth. Some gene expressions are tissue-specific. For example, MdMATE24 has high expression in parts of flower, especially in pollen. MdMATE23 expressed mainly in fruit and peel. While MdMATE62 is highly expressed in parts of flower except for pollen, MdMATE33 is highly expressed in central and lateral seed. The expression level of some genes gradually increases as the fruit matures (eg. MdMATE23, MdMATE49 and MdMATE58) and some genes were show the other way (eg. MdMATE2, MdMATE5 and MdMATE38). It suggests their putative roles during apple fruit development. These results show that most MdMATE genes have 


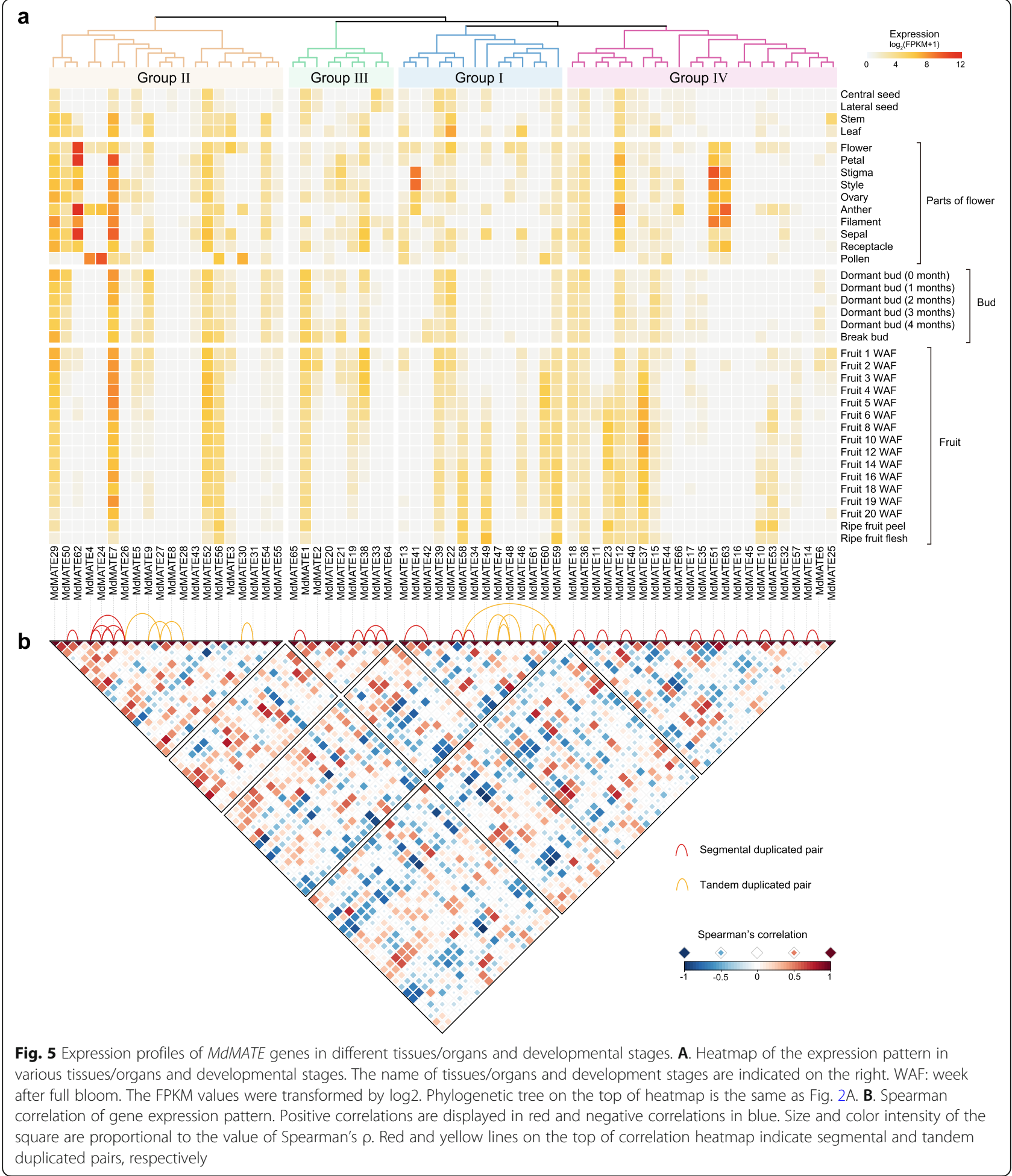

dynamic expressions in different tissues/organs or developmental stages. It can help us to explore the functional diversity of MdMATE genes in apple.

After gene duplication, the divergence of expression pattern of two copies is considered to be an important aspect in their functional differentiation [36, 37]. In the context of gene expression, it is straightforward to observe the function divergence after gene duplication [38]. Hence, correlation coefficient was calculated for the expression pattern of MdMATE gene pairs (Fig. 5B). The results show that genes in same group could differ considerably in their expression pattern, similar as before 
[39]. Among the 39 duplicated pairs, MdMATE4/ MdMATE26, MdMATE10/MdMATE53, MdMATE17/ MdMATE35, MdMATE50/MdMATE62, MdMATE51/ MdMATE63, MdMATE58/MdMATE59, and MdMATE59/MdMATE60 showed significant positive correlations (Spearman's $\rho>0.60, P<0.05$ ), and only one gene pair MdMATE22/MdMATE58 showed negative correlations (Spearman's $\rho=-0.62, P<0.05$ ). As novel expression patterns may also only occur in specific organs, we further investigate the correlation of expression patterns in three organs (flower, bud and fruit) [40] (Additional file 2: Fig. S3). Intriguingly, some duplicated pairs showed organ-specific correlation (MdMATE38/ MdMATE64 in flower, MdMATE13/MdMATE42 in bud and MdMATE1/MdMATE65 in fruit) (Additional file 2: Fig. S3). Additionally, in fruit, genes in same group showed higher than overall correlation. Almost all members in group III (green) showed positive correlation. In summary, these results indicated that the functions of MdMATE genes in apple tissues/organs and developmental stages may be widely correlated and varied. These paralogs with tissue-specific expression pattern has long been regarded as a precursor of future evolution which may contribute to phenotypic variation $[36,41]$.

\section{Cis-acting regulatory element analysis}

Gene transcription in plants is regulated by the cis-acting regulatory elements and transcription factors [42].. To identify putative cis-acting elements in the promoter region, we scanned the $1.5 \mathrm{~kb}$ upstream regions of transcriptional start site (TSS). All the candidate MdMATE gene promoters possessed typical TATA and CAAT boxes which are the core cis-acting element in eukaryotic promoter and enhancer regions (Additional file 1: Table S6). Other cis-acting regulatory elements were grouped into three main types based on their functional annotation: plant growth and development, phytohormone responsive and abiotic and biotic stress (Fig. 6). The abiotic and biotic stress group had the most number of regulatory elements, such as G-box, MBS and LTR, which were responsive to light inducible, drought

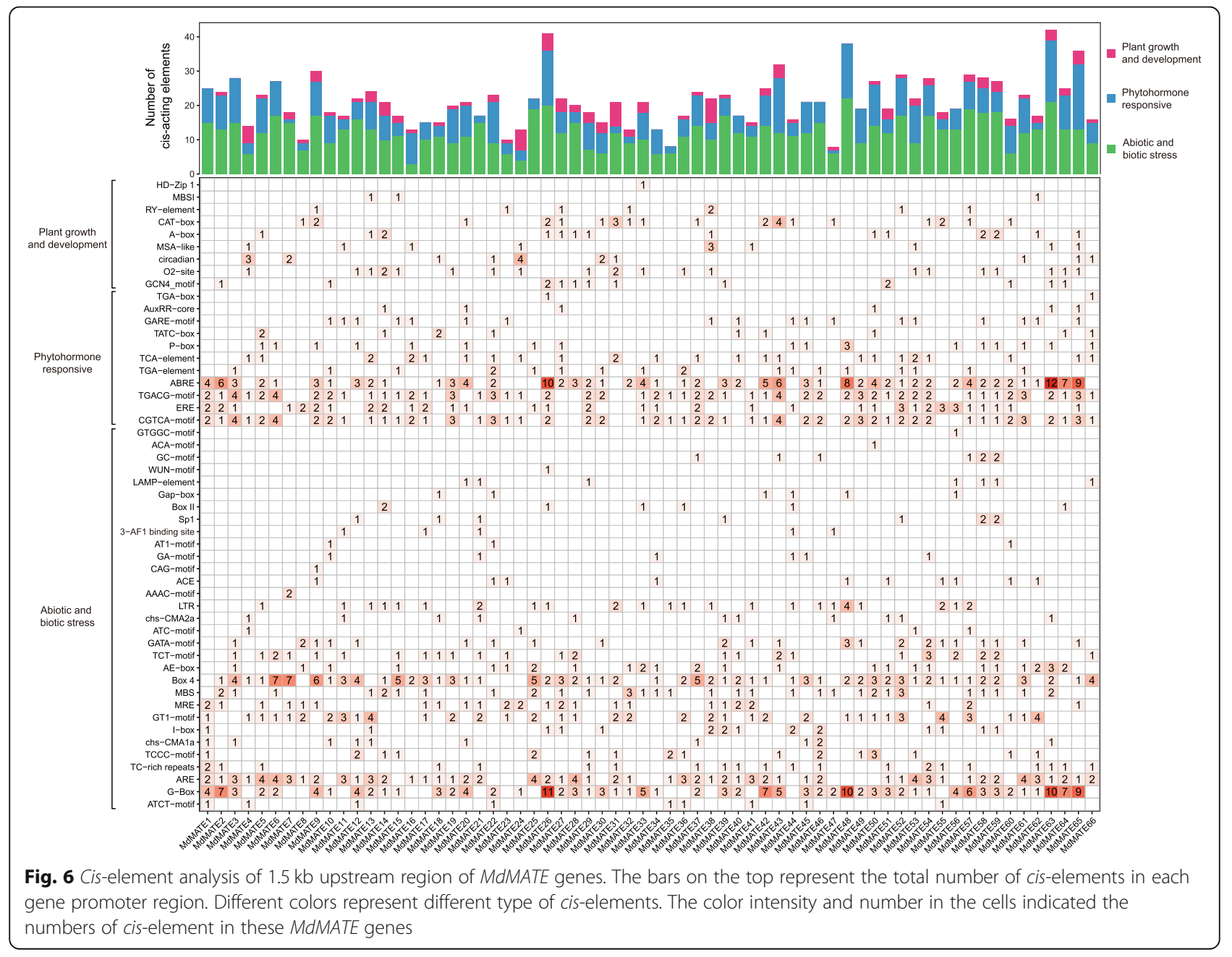


inducible and low-temperature stress, respectively. Many abiotic and biotic stress elements were observed in the promoter region of $M d M A T E$ genes, revealing that MdMATE genes play important roles on the stress response. The followed group is phytohormone responsive which has 11 elements, the ERE, ABRE, TGACG-motif and CGTCA-motif widely distributed among MdMATE members, which showed relatedness with Ethylene, Abscisic acid (ABA) and Methyl jasmonate (MeJA) responses, respectively. A total of nine cis-elements related to plant growth and development were also identified in some MdMATE gene promoter regions and the metabolism regulation element $\left(\mathrm{O}_{2}\right.$-site $)$ was found in 20 MdMATE genes. Various regulatory elements were identified, suggesting that the $M d M A T E$ genes play a crucial role in a wide range of biological processes in apple.

\section{Expression of MdMATE response to pathogen infection}

In apple and other fruits, the quality and yield can be greatly reduced in the presence of diseases [43]. An increasing body of evidence shows that the MATE genes are essential in conferring tolerance to abiotic and biotic stress factors [11, 21, 44].. To explore the role of $M d M A T E$ genes in response to disease, we analyzed the changes of transcription levels of MdMATE in response to Apple stem grooving virus (ASGV), Penicillium expansum (P. expansum) and Venturia inaequalis ( $V$. inaequalis). These three pathogens affect the quality and yield of apples, cause a lot of economic losses and waste. In the control before and after the ASGV infection, the expression levels of MdMATE57 showed up-regulated, while MdMATE22 showed down-regulated (Fig. 7). After $P$. expansum infection, a total of 16 and 7 genes were upregulated and down-regulated, respectively (Fig. 7). MdMATE7, MdMATE10, MdMATE13 and MdMATE50 barely expressed in $P$. expansum free, while their expression level in terms of FPKM increases to 94.76, 182.35, 65.64 and 82.61 after $P$. expansum infection, respectively (Additional file 1: Table S7). In contrast, MdMATE23,
MdMATE37 and MdMATE49 showed dramatical decrease after $P$. expansum infection. Apple scab is the most serious disease of apple worldwide in terms of the economic cost of control $[45,46]$. It is caused by $V$. inaequalis, a fungus that can cause the apple disease. Scab can be found in almost all areas in which apples are grown commercially. Here we analyzed the MdMATE gene expression levels of different stages after $V$. inaequalis infection (Fig. 7). Some genes showed upregulated after infecting by $V$. inaequalis such as MdMATE2, MdMATE7 and MdMATE9, whereas some genes showed down-regulated such as MdMATE3, MdMATE15 and MdMATE46. The expression level of MdMATE6, MdMATE59, MdMATE62 and MdMATE64 increased after 8 days of infection. These results indicated the MATE gene family in apple have a diverse function in responses to biotic stress, especially for $P$. expansum infection.

\section{Discussion}

Recently, the genome-wide analysis of MATE gene family in different species has been gradually carried out, suggesting their diverse function involved in stress responses, plant growth and transmembrane transport. In this study, we carried out a comprehensive analysis of MATE gene family in apple. We identified 66 MdMATE genes from the 'Golden Delicious' reference genome, including two genes that have been reported. We conducted phylogenetic, gene structure, motif pattern, synteny and evolutionary analysis. Besides, the expression patterns of MdMATE genes in different tissues/organs and developmental stages were also explored. The cis-element analysis shows that MdMATE genes are widely involved in stress response in apples. Hence, we also compared the changes in MdMATE gene expression before and after three different pathogen infections.

A total of 66 MdMATE genes were identified in apple. The MATE members in apple exceed those in Arabidopsis (56 members, 135 Mb) [10], potato (48 members,

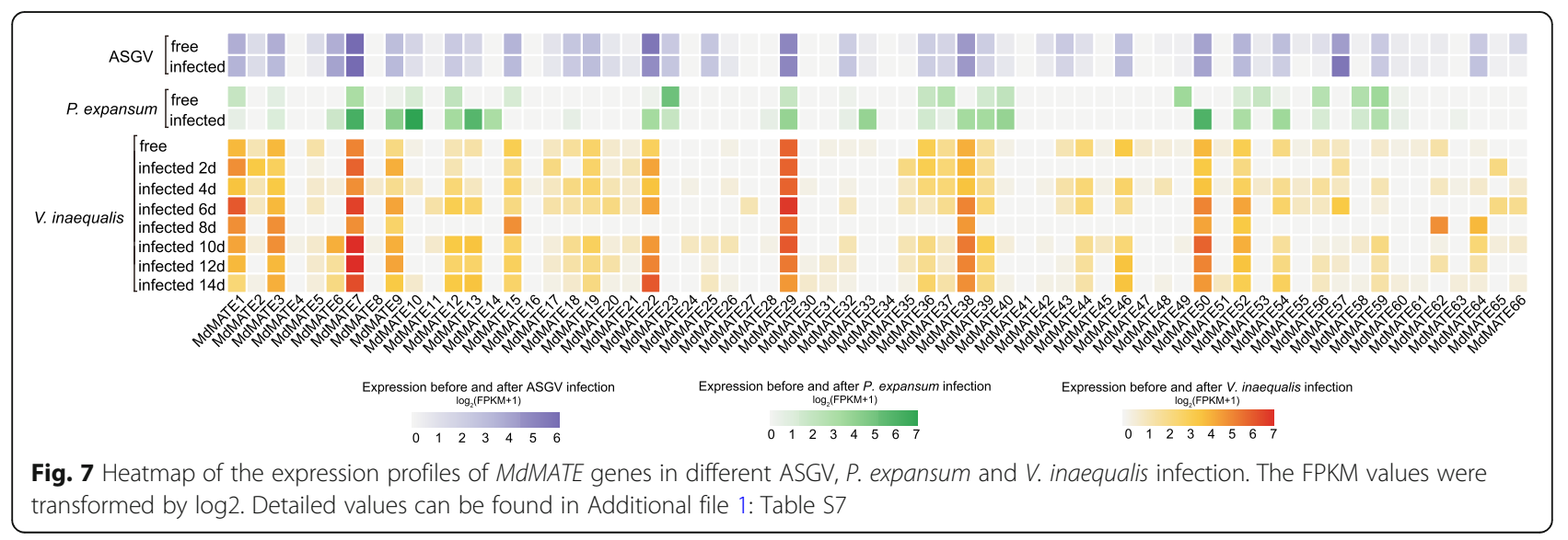


$674 \mathrm{Mb}$ ) [6], maize (49 members, $2300 \mathrm{Mb})$ [15] and rice (45 members, $\sim 380 \mathrm{Mb}$ ) [16], but family size is inferior to soybean (117 members, $\sim 978 \mathrm{Mb}$ ) [17]. The number of MATE genes is not paralleled to the size of genome and there is no absolute correlation with genome size. However, in dicots, it was paralleled to the genome size and generally have more members than monocots. Further synteny analysis showed there are more collinear gene pairs between apple and dicots than monocots. We speculated that the expansion of MATE gene family mainly occurs during the evolution of dicots.

Phylogenetic analysis divides the MdMATE genes into four groups based on the classifications on AtDTX proteins (Fig. 1). In group I, the MdMATE lost five members, while group II, III and IV gained four, three and eight members, respectively. Group I contains 14 MdMATE transporters along with 19 AtDTX transporters. Among them, the AtDTX1, which is the first plant protein that has been shown to function as a detoxifying efflux carrier, can mediate the efflux of plantderived or exogenous toxic compounds from the cytoplasm [10]. The AtDTX14 and AtDTX18 can export norfloxacin and prevent Arabidopsis colonization by $P$. infestans, respectively [47, 48]. The AtDTX19 is expressed in root epidermal cells and necessary for protecting roots from toxic compounds in the soil [12]. Group II contain 20 MdMATE transporters along with 16 AtDTX transporters. Among them, the AtDTX21 plays an important role in Atrazine detoxification [49]. The AtDTX30, AtDTX31, AtDTX33 and AtDTX35 control root hair development in Arabidopsis [50, 51]. Besides, the AtDTX30 also involve in aluminum tolerance and indirectly modulated citrate exudation [52]. Group III contain 9 MdMATE transporters along with 6 MATE transporters from Arabidopsis. The AtDTX41/TRANSPARENT TESTA 12 (TT12) had been functionally characterized that can mediates anthocyanin transport in vitro [13]. Its homologs in apple, MdMATE1 and $M d M A T E 2$, are vacuolar flavonoid transporter which are active in proanthocyanidins accumulating cells of apple fruit [22]. In the two subgroups of group IV, the group IV-a contain 9 and 6 MATE transporters from apple and Arabidopsis, respectively. The AtDTX42 can facilitate AI-activated citrate exudation independently from and along with AtALMT1 to confer a full expression of Arabidopsis AI tolerance [53, 54]. The AtDTX43 plays a major role in iron and zinc homeostasis in Arabidopsis and transports citrate [55]. The AtDTX47 is related to the transport of salicylic acid or its precursor [56]. While 14 MdMATE transporters and 9 AtDTX transporters in the group IV-b. The AtDTX48 is related to multiple functions, including organ initiation, iron homeostasis and hypocotyl cell elongation [57-59]. The AtDTX50 can transport abscisic acid (ABA) and respond to drought conditions [18]. The function of AtDTX51 is related to hypocotyl cell elongation same as AtDTX48, but additionally has the functions of regulates plant disease resistance and affects plant architecture [60, 61]. The AtDTX51 and AtDTX52 control senescence and iron homeostasis in plants [62, 63]. The AtDTX54 and AtDTX55 have a conserved function in the regulation of lateral organ initiation in plants [19]. The AtDTX56 can repress a protein kinase that negatively regulates $\mathrm{CO}_{2}$ induced stomatal closing [64]. From the functions of these homologous AtDTX transporters in the subgroups of group IV, the function of group IV-a is mainly related to ion tolerance and in group IV-b, it is also related to developmental and disease resistance in addition to the functions similar as group IV-a. Overall, Arabidopsis MATE members in the same group have highly diverse functions, indicating MATE in apple may also have multitasking ability.

In group I, only four AtDTX genes (AtDTX1, AtDTX14, AtDTX18 and AtDTX19) [10, 12, 47, 48] were functionally characterized but no duplicated MdMATE genes pairs clustered together with these AtDTX genes. However, in group IV, duplicated $M d M A T E$ genes pairs such as MdMATE12/MdMATE40, MdMATE15/ MdMATE44, MdMATE18/MdMATE36, MdMATE57/ MdMATE32, MdMATE53/MdMATE10, MdMATE45/ MdMATE16, MdMATE17/MdMATE35 and MdMATE51/MdMATE63 were clustered together with AtDTX42, AtDTX44, AtDTX46, AtDTX48, AtDTX51, AtDTX53, AtDTX54 and AtDTX55, respectively. Some of these AtDTX genes are involved in diverse mechanisms that are indispensable to plant growth and development: the AtDTX42 is related with AI tolerance [53, 55]; the AtDTX48, AtDTX51, AtDTX54 and AtDTX55 all related to plant growth [19,57-61]. The duplicated MdMATE gene pairs retained during the evolution process of apple may have similar functions with these neighbor AtDTX genes.

Different expression patterns of MdMATE genes were observed in various tissues/organs and developmental stages. It is worth noting that MdMATE7 and MdMATE36 are expressed in all samples in our study. These two genes may be important for maintenance of apple growth and development. Furthermore, expression correlation analysis reveals that MdMATE duplicates may follow different functional models (Additional file 1: Table S3). MdMATE51/MdMATE63 have strong positive correlation (Spearman's $\rho=0.878, P<0.001$ ) in flower. Both their expression levels were relatively high. The corresponding gene dosage increase may be beneficial for organism [38]. MdMATE22/MdMATE58 show strong negative correlations (Spearman's $\rho=-0.882, P<$ 0.001 ) in fruit developmental stages. In the early stages, 
MdMATE22 expression level was higher than MdMATE58, but opposite in the late fruit development stage. This suggested that sub-functionalization probably occurred between the pair of genes $[38,65]$.

Cis-elements analysis further confirmed the versatility of MATE gene family and its major role in response to stress. By analyzing changes in the expression levels of $M d M A T E$ genes before and after infection of three pathogens that have a great impact on the quality and yield of apples, suggesting that MdMATE genes are involved in apple response to pathogen infection, especially for $P$. expansum infection. Notably, MdMATE7 is involved in both infections by $P$. expansum and $V$. inaequalis (Fig. 7), and this gene is expressed in all tissue/organs. Thus, we speculated that the sustained expression of MdMATE7 is important for apple growth and stress response. Additionally, the promoter regions of all MdMATE genes contain many stress response cis-elements and we further speculated that the other genes, which are not involved in the three pathogens infections has great potential for stress response.

\section{Conclusions}

In this study, a total of 66 MATE (MdMATE) genes encoding MATE transporters were identified in the apple genome. We classified these MdMATE genes into four groups by phylogenetic analysis with MATE genes in Arabidopsis. Synteny analysis reveals that whole genome duplication and segmental duplication events played a major role in the expansion of MATE gene family in apple. MdMATE genes show diverse expression patterns in different tissues/organs and developmental stages. Analysis of cis-regulatory elements in MdMATE promoter regions indicates that the function of MdMATE gene is mainly related to stress response. Besides, the changes of gene expression levels upon different pathogen infections reveal that MdMATE genes are involved in biotic stress response. Our results provide insights for a more comprehensive understanding of the MATE gene family function in apple and provide valuable resources for apple disease resistance research.

\section{Methods}

\section{Identification of MATE transporters in apple genome}

A total of 56 MATE family members in Arabidopsis as previously reported [10] were download from The Arabidopsis Information Resource (TAIR) (https://www. arabidopsis.org/). A total of 101 apple putative MATE protein sequences were retrieved by BLASTP searches against the target apple proteome, GDDH13 v1.1 [23], using 56 A.thaliana MATE protein sequences as queries (E-value $\leq 10^{-7}$ ) (Additional file 1: Table S1). To obtain more accurate MATE members in apple, manual filtering for the putative MATE protein sequences was performed as previously described [28]. Briefly, the putative MATE protein sequences were filtered by the presence of conserved MATE domain (Pfam: PF01554) using the HMMER (https://www.ebi.ac.uk/Tools/hmmer/ search/hmmscan) [66], the Conserved Domain Database (CDD, https://www.ncbi.nlm.nih.gov/Structure/cdd/ wrpsb.cgi) [67] and the Simple Modular Architecture Research Tool (SMART, http://smart.embl-heidelberg. de/smart/batch.pl) [68]. All these putative sequences were assessed against the expected features of the MATE transporters in plants (e.g., containing MatE domains, 8-12 transmembrane domains and classified as MATE_like superfamily) (Additional file 1: Table S1). Finally, a total of 66 apple MATE proteins were identified. Physical parameters such as theoretical isoelectric point (pI), molecular weight (MW) and instability index (II) were calculated by ProtParam (https://web.expasy.org/protparam/) [69]. The subcellular localization of the MATE proteins were predicted using WoLF PSORT [70].

\section{Chromosomal distribution and gene duplication analysis of MdMATE family}

The physical location information of all 66 MdMATE genes were obtained from the apple genome annotation gff3 format file and visualize through Circlize package [71]. WGD/segmental and tandem duplication events were detected by MCScanX [72] with default parameters. Tandem clusters were defined as previously report: genes in a cluster need to be on the same chromosome and not more than one gene apart [73]. To exhibit the synteny relationship of the orthologous MATE genes in apple and other four species, MATE gene family members in Arabidopsis, soybean, maize and rice were obtained as the previous report [10,15-17] and sequence files were download from Phytozome database (v12, https://phytozome.jgi.doe.gov/pz/portal.html) [74]. Species tree were obtained from TimeTree(http://www. timetree.org) [75]. Then MCScanX pipeline [33] was used to construct syntenic maps and visualization. $\mathrm{Ka} / \mathrm{Ks}$ values between homologous were calculated by KaKs Calculator 2.0 [76].

\section{Phylogenetic and gene structural analysis}

All the 122 MATE protein sequences in apple and Arabidopsis were used to perform phylogenetic and structural analysis. Multiple sequence alignments were conducted by ClustalW in MEGA X with default parameters and ProteinWeightMatrix $=$ BLOSUM [77]. The alignment result was then used to construct a phylogenetic tree based on the neighbor-joining (NJ) method of MEGA X, with the following setups: Equal input model and partial deletion (60\%). For the maximum likelihood (ML) tree, JTT $+\mathrm{F}+\mathrm{G}$ was used as the best model for ML tree constructing which calculated by ProtTest 3.4.2 
[78], the ML tree was constructed by MEGA X. Both NJ and ML trees were conducted 1000 bootstrap replications.

Gene structure analysis was performed using the Gene Structure Display Server (GSDS) [79] with default setting. Motifs in MATE proteins were identified using MEME Suite [25] (version 5.1.1, http://meme-suite.org/ index.html) with default setting: site distribution is zero or one occurrence per sequence (zoops), motif width is 5 to 50 and the maximum number of motifs was set at 12. We extract the $1.5 \mathrm{~kb}$ upstream region of MdMATE genes and upload to PlantCARE [80] database to detect cis-regulatory elements in the promoter regions.

\section{Expression pattern of MdMATE genes in different tissues and pathogen infection}

We obtain a total of 48 expression profiles of 66 MdMATE genes from Apple Multi-Dimensional Omics Database (AppleMDO) [35]. These profiles including 36 tissues/organs and different development stage (central seed, lateral seed, stem, leaf, flower, petal, stigma, style, ovary, anther, filament, sepal, receptacle, pollen, four dormant bud stage, break bud, fourteen fruit developmental stages from 1 week after full-bloom (WAF1) to harvest (WAF20), ripe fruit peel and flesh and control data of three pathogens infection. In the database, all the RNA-seq data were already quality controlled and FPKM values can be extracted from the database. Expression heatmaps were made by Pheatmap package with pheatmap2 function [81]. Spearman correlation was conducted using the cor() function in R-4.0.2 (https://www. r-project.org/).

\begin{abstract}
Abbreviations
ABA: Transport abscisic acid; ABC: ATP-binding cassette superfamily; ASGV: Apple stem grooving virus; FPKM: Fragments Perk Kilobase per Million; MATE: Multidrug and toxic compound extrusion; MFS: Major facilitator superfamily; MW: Molecular weight; NJ: Neighbor-joining; pl: Theoretical isoelectric point; RND: Resistance/nodulation/division family; SMR: Small gene
\end{abstract} multidrug resistance family; WGD: Whole genome duplication

\section{Supplementary Information}

The online version contains supplementary material available at https://doi. org/10.1186/s12864-021-07943-1.

Additional file 1 Table S1. Manual filtering of 101 putative MATE proteins. Table S2. Details of the 66 MdMATE genes in apple. Table S3. Duplicated gene pairs of MdMATE genes and expression pattern

correlations. Table S4. Collinear gene pairs between MdMATE genes and MATE genes in other species. Table S5. FPKM of MdMATE genes in different tissues/organs and developmental stages. Table S6. Ciselements of MdMATE genes. Table S7. FPKM of MdMATE genes with three pathogen infections.

Additional file 2 Fig. S1. The unrooted neighbor-joining phylogenetic tree of MATE family members in apple and Arabidopsis. The different colors indicate different groups (Group I in blue, Group II in orange, Group III in green and Group IV in pink). 'MdMATE' represents MATE members from apple, 'AtDTX' represents MATE members from Arabidopsis. Numbers on the nodes are bootstrap values in percentage (1000 replicates). Fig. S2. The conserved motifs among MdMATE proteins. Fig. S3. Spearman correlation of gene expression pattern in flower, bud and fruit. Positive correlations are displayed in red and negative correlations in blue color. Size and color intensity of the square are proportional to the Spearman's $\rho$. Red and yellow lines on the top of correlation heatmap indicate segmental and tandem duplicated pairs, respectively.

\section{Acknowledgements}

The authors thank to lab members for assistance.

\section{Authors' contributions}

Li.L. and W.Z. conceptualization this study. W.Z., Liao.L. and J.X. perform bioinformatic analyses. Liao.L. and Y.H. helped with results

interpretation. W.Z. wrote the initial manuscript. Li.L. and Y.H. critically reviewed and edited the article. All authors have read and agreed to the published version of the manuscript. The authors read and approved the final manuscript

\section{Funding}

The research was funded by Huazhong Agricultural University Scientific \& Technological Self-innovation Foundation to Li.L and supported by Hubei Hongshan Laboratory to Li.L. The funding bodies played no role in the design of the study and collection, analysis, and interpretation of data and in writing the manuscript.

\section{Availability of data and materials}

The reference genome were GDDH13 Version 1.1 and obtained from The Apple Genome and Epigenome (https://iris.angers.inra.fr/gddh13/the-applegenome-downloads.html). All data analyzed during this study are included in this article and its Additional files. MdMATE gene names and details can be found in Additional file 1: Table S1 and S2. The Ka/Ks and spearman's correlation coefficient of each gene pairs can be found in Additional file 1: Table S3 and Table S4. The FPKM value of MdMATE genes in different tissues/organs and pathogen infections can be found in Additional file 1: Table S5 and Table S7. The cis-elements annotations of MdMATE genes can be found in Additional file 1: Table S5.

\section{Declarations}

Ethics approval and consent to participate Not applicable.

\section{Consent for publication}

Not applicable.

\section{Competing interests}

The authors declare that they have no competing interests.

\section{Author details}

${ }^{1}$ Hubei Key Laboratory of Agricultural Bioinformatics, College of Informatics, Huazhong Agricultural University, Wuhan 430070, People's Republic of China. ${ }^{2}$ CAS Key Laboratory of Plant Germplasm Enhancement and Specialty Agriculture, Wuhan Botanical Garden, The Innovative Academy of Seed Design, Chinese Academy of Sciences, Wuhan 430074, People's Republic of China. ${ }^{3}$ Hubei Hongshan Laboratory, Huazhong Agricultural University, Wuhan 430070, People's Republic of China.

Received: 30 March 2021 Accepted: 12 August 2021

Published online: 30 August 2021

References

1. Omote H, Hiasa M, Matsumoto T, Otsuka M, Moriyama Y. The MATE proteins as fundamental transporters of metabolic and xenobiotic organic cations. Trends Pharmacol Sci. 2006;27(11):587-93. https://doi.org/10.1016/j.tips.2006. 09.001

2. Remy E, Duque P. Beyond cellular detoxification: a plethora of physiological roles for MDR transporter homologs in plants. Front Physiol. 2014;5:201.

3. Putman M, van Veen HW, Konings WN. Molecular properties of bacterial multidrug transporters. Microbiol Mol Biol Rev. 2000;64(4):672-93. https:// doi.org/10.1128/MMBR.64.4.672-693.2000. 
4. Wang R, Zhao P, Kong N, Lu R, Pei Y, Huang C, Ma H, Chen Q. GenomeWide Identification and Characterization of the Potato bHLH Transcription Factor Family. Genes (Basel). 2018;9(1).

5. Saier MH Jr. Genome archeology leading to the characterization and classification of transport proteins. Curr Opin Microbiol. 1999;2(5):555-61. https://doi.org/10.1016/S1369-5274(99)00016-8.

6. Li Y, He H, He LF. Genome-wide analysis of the MATE gene family in potato. Mol Biol Rep. 2019;46(1):403-14. https://doi.org/10.1007/s11033-018-4487-y.

7. Morita Y, Kodama K, Shiota S, Mine T, Kataoka A, Mizushima T, et al. NorM, a putative multidrug efflux protein, of Vibrio parahaemolyticus and its homolog in Escherichia coli. Antimicrob Agents Chemother. 1998;42(7): 1778-82. https://doi.org/10.1128/AAC.42.7.1778.

8. Pao SS, Paulsen IT, Saier MH. Major facilitator superfamily. Microbiol Mol Biol Rev. 1998;62(1):1-34. https://doi.org/10.1128/MMBR.62.1.1-34.1998.

9. Brown MH, Paulsen IT, Skurray RA. The multidrug efflux protein NorM is a prototype of a new family of transporters. Mol Microbiol. 1999;31(1):394-5. https://doi.org/10.1046/j.1365-2958.1999.01162.x.

10. Li L, He Z, Pandey GK, Tsuchiya T, Luan S. Functional cloning and characterization of a plant efflux carrier for multidrug and heavy metal detoxification. J Biol Chem. 2002;277(7):5360-8. https://doi.org/10.1074/jbc. M108777200.

11. Upadhyay N, Kar D, Deepak Mahajan B, Nanda S, Rahiman R, Panchakshari $\mathrm{N}$, et al. The multitasking abilities of MATE transporters in plants. J Exp Bot. 2019;70(18):4643-56. https://doi.org/10.1093/jxb/erz246.

12. Diener AC, Gaxiola RA, Fink GR. Arabidopsis ALF5, a multidrug efflux transporter gene family member, confers resistance to toxins. Plant Cell. 2001;13(7):1625-38. https://doi.org/10.1105/TPC.010035.

13. Marinova K, Pourcel L, Weder B, Schwarz M, Barron D, Routaboul JM, et al. The Arabidopsis MATE transporter $\Pi 12$ acts as a vacuolar flavonoid/H+ -antiporter active in proanthocyanidin-accumulating cells of the seed coat. Plant Cell. 2007;19(6):2023-38. https://doi.org/10.1105/tpc.106.046029.

14. Santos ALD, Chaves-Silva S, Yang L, Maia LGS, Chalfun-Junior A, Sinharoy S, et al. Global analysis of the MATE gene family of metabolite transporters in tomato. BMC Plant Biol. 2017;17(1):185. https://doi.org/10.1186/s12870-01 7-1115-2.

15. Zhu H, Wu J, Jiang $Y$, Jin J, Zhou W, Wang $Y$, et al. Genomewide analysis of MATE-type gene family in maize reveals microsynteny and their expression patterns under aluminum treatment. J Genet. 2016;95(3):691-704. https:// doi.org/10.1007/s12041-016-0686-2.

16. Wang L, Bei X, Gao J, Li Y, Yan Y, Hu Y. The similar and different evolutionary trends of MATE family occurred between rice and Arabidopsis thaliana. BMC Plant Biol. 2016;16(1):207. https://doi.org/10.1186/s12870-016-0895-0.

17. Liu J, Li Y, Wang W, Gai J, Li Y. Genome-wide analysis of MATE transporters and expression patterns of a subgroup of MATE genes in response to aluminum toxicity in soybean. BMC Genomics. 2016;17(1):223. https://doi. org/10.1186/s12864-016-2559-8.

18. Zhang H, Zhu H, Pan Y, Yu Y, Luan S, Li L. A DTX/MATE-type transporter facilitates abscisic acid efflux and modulates ABA sensitivity and drought tolerance in Arabidopsis. Mol Plant. 2014;7(10):1522-32. https:/doi.org/10.1093/mp/ssu063.

19. Suzuki M, Sato Y, Wu S, Kang BH, McCarty DR. Conserved functions of the MATE transporter BIG EMBRYO1 in regulation of lateral organ size and initiation rate. Plant Cell. 2015;27(8):2288-300. https:/doi.org/10.1105/tpc.15.00290.

20. Sheikh MA, Mushtaq K, Mir Jl, Amin M, Nabi SU. Introgression of scab resistance gene Vf (Rvi6) in commercially grown susceptible cultivar Fuji Azitec of apple (Malus domestica) using marker assisted selection. Res J Biotechnol Vol. 2020;15:9

21. Tiwari M, Sharma D, Singh M, Tripathi RD, Trivedi PK. Expression of OsMATE1 and OsMATE2 alters development, stress responses and pathogen susceptibility in Arabidopsis. Sci Rep. 2014;4:3964.

22. Frank S, Keck M, Sagasser M, Niehaus K, Weisshaar B, Stracke R. Two differentially expressed MATE factor genes from apple complement the Arabidopsis transparent testa12 mutant. Plant Biol. 2011;13(1):42-50. https:// doi.org/10.1111/j.1438-8677.2010.00350.x.

23. Daccord N, Celton JM, Linsmith G, Becker C, Choisne N, Schijlen E, et al. High-quality de novo assembly of the apple genome and methylome dynamics of early fruit development. Nat Genet. 2017;49(7):1099-106. https://doi.org/10.1038/ng.3886

24. Li N, Meng H, Xing H, Liang L, Zhao X, Luo K. Genome-wide analysis of MATE transporters and molecular characterization of aluminum resistance in Populus. J Exp Bot. 2017;68(20):5669-83. https://doi.org/10.1093/jxb/erx370.
25. Bailey TL, Boden M, Buske FA, Frith M, Grant CE, Clementi L, et al. MEME SUITE: tools for motif discovery and searching. Nucleic Acids Res. 2009; 37(Web Server issue):W202-8

26. Yamasaki K, Kigawa T, Seki M, Shinozaki K, Yokoyama S. DNA-binding domains of plant-specific transcription factors: structure, function, and evolution. Trends Plant Sci. 2013;18(5):267-76. https://doi.org/10.1016/j.tpla nts.2012.09.001

27. Xu L, Shen ZL, Chen W, Si GY, Meng Y, Guo N, et al. Phylogenetic analysis of upland cotton MATE gene family reveals a conserved subfamily involved in transport of proanthocyanidins. Mol Biol Rep. 2019;46(1):161-75. https://doi. org/10.1007/s11033-018-4457-4.

28. Ali E, Saand MA, Khan AR, Shah JM, Feng S, Ming C, et al. Genome-wide identification and expression analysis of detoxification efflux carriers (DTX) genes family under abiotic stresses in flax. Physiol Plant. 2020;171(4):483501. https://doi.org/10.1111/ppl.13105.

29. See DR, Brooks S, Nelson JC, Brown-Guedira G, Friebe B, Gill BS. Gene evolution at the ends of wheat chromosomes. Proc Natl Acad Sci U S A. 2006;103(11):4162-7. https://doi.org/10.1073/pnas.0508942102.

30. Moore RC, Purugganan MD. The early stages of duplicate gene evolution. Proc Natl Acad Sci U S A. 2003;100(26):15682-7. https://doi.org/10.1073/pna s.2535513100.

31. Xie T, Chen C, Li C, Liu J, Liu C, He Y. Genome-wide investigation of WRKY gene family in pineapple: evolution and expression profiles during development and stress. BMC Genomics. 2018;19(1):490. https://doi.org/1 0.1186/s12864-018-4880-x

32. Cannon SB, Mitra A, Baumgarten A, Young ND, May G. The roles of segmental and tandem gene duplication in the evolution of large gene families in Arabidopsis thaliana. BMC Plant Biol. 2004;4(1):10. https://doi. org/10.1186/1471-2229-4-10

33. Tang $H$, Bowers JE, Wang $X$, Ming $R$, Alam M, Paterson AH. Synteny and collinearity in plant genomes. Science. 2008;320(5875):486-8. https://doi. org/10.1126/science.1153917.

34. Schmutz J, Cannon SB, Schlueter J, Ma J, Mitros T, Nelson W, et al. Genome sequence of the palaeopolyploid soybean. Nature. 2010;463(7278):178-83. https://doi.org/10.1038/nature08670.

35. Da L, Liu Y, Yang J, Tian T, She J, Ma X, et al. AppleMDO: a multidimensional omics database for apple co-expression networks and chromatin states. Front Plant Sci. 2019;10:1333. https://doi.org/10.3389/fpls.2 019.01333.

36. Ohno S: Evolution by gene duplication: Springer Science \& Business Media; 2013

37. Li W-H, Yang J, Gu X. Expression divergence between duplicate genes. Trends Genet. 2005;21(11):602-7. https://doi.org/10.1016/j.tig.2005.08.006.

38. Panchy N, Lehti-Shiu M, Shiu SH. Evolution of gene duplication in plants. Plant Physiol. 2016;171(4):2294-316. https://doi.org/10.1104/pp.16.00523.

39. Schilling S, Kennedy A, Pan S, Jermiin LS, Melzer R. Genome-wide analysis of MIKC-type MADS-box genes in wheat: pervasive duplications, functional conservation and putative neofunctionalization. New Phytol. 2020;225(1): 511-29. https://doi.org/10.1111/nph.16122.

40. Hughes TE, Langdale JA, Kelly S. The impact of widespread regulatory neofunctionalization on homeolog gene evolution following wholegenome duplication in maize. Genome Res. 2014;24(8):1348-55. https://doi. org/10.1101/gr.172684.114

41. Buggs RJ, Elliott NM, Zhang L, Koh J, Viccini LF, Soltis DE, et al. Tissuespecific silencing of homoeologs in natural populations of the recent allopolyploid Tragopogon mirus. New Phytol. 2010;186(1):175-83. https:// doi.org/10.1111/j.1469-8137.2010.03205.x.

42. Wittkopp PJ, Kalay G. Cis-regulatory elements: molecular mechanisms and evolutionary processes underlying divergence. Nat Rev Genet. 2011;13(1): 59-69. https://doi.org/10.1038/nrg3095.

43. Dubey SR, Jalal AS. Apple disease classification using color, texture and shape features from images. SIViP. 2016;10(5):819-26. https://doi.org/10.1 007/s11760-015-0821-1.

44. Takanashi K, Shitan N, Yazaki K. The multidrug and toxic compound extrusion (MATE) family in plants. Plant Biotechnol. 2014;31(5):417-30. https://doi.org/10.5511/plantbiotechnology.14.0904a.

45. Carisse O, Bernier J. Effect of environmental factors on growth, pycnidial production and spore germination of Microsphaeropsis isolates with biocontrol potential against apple scab. Mycol Res. 2002;106(12):1455-62. https://doi.org/10.1017/S0953756202006858 
46. Bowen JK, Mesarich CH, Bus VG, Beresford RM, Plummer KM, Templeton MD. Venturia inaequalis: the causal agent of apple scab. Mol Plant Pathol. 2011;12(2):105-22. https://doi.org/10.1111/j.1364-3703.2010.00656.x.

47. Miyauchi H, Moriyama S, Kusakizako T, Kumazaki K, Nakane T, Yamashita K, et al. Structural basis for xenobiotic extrusion by eukaryotic MATE transporter. Nat Commun. 2017;8(1):1633. https://doi.org/10.1038/s41467-01 7-01541-0

48. Dobritzsch M, Lubken T, Eschen-Lippold L, Gorzolka K, Blum E, Matern A, et al. MATE transporter-dependent export of Hydroxycinnamic acid amides. Plant Cell. 2016;28(2):583-96. https://doi.org/10.1105/tpc.15.00706.

49. Ramel F, Sulmon C, Cabello-Hurtado F, Taconnat L, Martin-Magniette ML, Renou JP, et al. Genome-wide interacting effects of sucrose and herbicidemediated stress in Arabidopsis thaliana: novel insights into atrazine toxicity and sucrose-induced tolerance. BMC Genomics. 2007;8(1):450. https://doi. org/10.1186/1471-2164-8-450.

50. Won SK, Lee YJ, Lee HY, Heo YK, Cho M, Cho HT. Cis-element- and transcriptome-based screening of root hair-specific genes and their functional characterization in Arabidopsis. Plant Physiol. 2009;150(3):145973. https://doi.org/10.1104/pp.109.140905.

51. Zhang H, Zhao FG, Tang RJ, Yu Y, Song J, Wang Y, et al. Two tonoplast MATE proteins function as turgor-regulating chloride channels in Arabidopsis. Proc Natl Acad Sci U S A. 2017;114(10):E2036-45. https://doi. org/10.1073/pnas.1616203114.

52. Upadhyay N, Kar D, Datta S. A multidrug and toxic compound extrusion (MATE) transporter modulates auxin levels in root to regulate root development and promotes aluminium tolerance. Plant Cell Environ. 2020; 43(3):745-59. https://doi.org/10.1111/pce.13658.

53. Liu J, Magalhaes JV, Shaff J, Kochian LV. Aluminum-activated citrate and malate transporters from the MATE and ALMT families function independently to confer Arabidopsis aluminum tolerance. Plant J. 2009; 57(3):389-99. https://doi.org/10.1111/j.1365-313X.2008.03696.X.

54. Liu J, Luo X, Shaff J, Liang C, Jia X, Li Z, et al. A promoter-swap strategy between the AtALMT and AtMATE genes increased Arabidopsis aluminum resistance and improved carbon-use efficiency for aluminum resistance. Plant J. 2012;71(2):327-37. https://doi.org/10.1111/j.1365-313X.2012.04994.X

55. Scheepers M, Spielmann J, Boulanger M, Carnol M, Bosman B, De Pauw E, et al. Intertwined metal homeostasis, oxidative and biotic stress responses in the Arabidopsis frd3 mutant. Plant J. 2020;102(1):34-52. https://doi.org/1 $0.1111 /$ tpj. 14610 .

56. Nawrath C, Heck S, Parinthawong N, Metraux JP. EDS5, an essential component of salicylic acid-dependent signaling for disease resistance in Arabidopsis, is a member of the MATE transporter family. Plant Cell. 2002; 14(1):275-86. https://doi.org/10.1105/tpc.010376.

57. Burko Y, Geva Y, Refael-Cohen A, Shleizer-Burko S, Shani E, Berger Y, et al. From organelle to organ: ZRIZI MATE-type transporter is an organelle transporter that enhances organ initiation. Plant Cell Physiol. 2011;52(3):51827. https://doi.org/10.1093/pcp/pcr007.

58. Seo PJ, Park J, Park MJ, Kim YS, Kim SG, Jung JH, et al. A Golgi-localized MATE transporter mediates iron homoeostasis under osmotic stress in Arabidopsis. Biochem J. 2012;442(3):551-61. https://doi.org/10.1042/BJ2 0111311.

59. Wang R, Liu X, Liang S, Ge Q, Li Y, Shao J, et al. A subgroup of MATE transporter genes regulates hypocotyl cell elongation in Arabidopsis. J Exp Bot. 2015;66(20):6327-43. https://doi.org/10.1093/jxb/erv344.

60. Li R, Li J, Li S, Qin G, Novak O, Pencik A, et al. ADP1 affects plant architecture by regulating local auxin biosynthesis. PLoS Genet. 2014;10(1): e1003954. https://doi.org/10.1371/journal.pgen.1003954.

61. Sun X, Gilroy EM, Chini A, Nurmberg PL, Hein I, Lacomme C, et al. ADS1 encodes a MATE-transporter that negatively regulates plant disease resistance. New Phytol. 2011;192(2):471-82. https://doi.org/10.1111/j.14698137.2011.03820.x

62. Jia M, Liu X, Xue H, Wu Y, Shi L, Wang R, et al. Noncanonical ATG8-ABS3 interaction controls senescence in plants. Nat Plants. 2019;5(2):212-24. https://doi.org/10.1038/s41477-018-0348-x.

63. Wang Z, Qian C, Guo X, Liu E, Mao K, Mu C, et al. ELS1, a novel MATE transporter related to leaf senescence and iron homeostasis in Arabidopsis thaliana. Biochem Biophys Res Commun. 2016;476(4):319-25. https://doi. org/10.1016/j.bbrc.2016.05.121.

64. Tian W, Hou C, Ren Z, Pan Y, Jia J, Zhang H, et al. A molecular pathway for CO(2) response in Arabidopsis guard cells. Nat Commun. 2015;6(1):6057. https://doi.org/10.1038/ncomms7057.
65. Force A, Lynch M, Pickett FB, Amores A, Yan YL, Postlethwait J. Preservation of duplicate genes by complementary, degenerative mutations. Genetics. 1999;151(4):1531-45. https://doi.org/10.1093/genetics/151.4.1531.

66. El-Gebali S, Mistry J, Bateman A, Eddy SR, Luciani A, Potter SC, et al. The Pfam protein families database in 2019. Nucleic Acids Res. 2019;47(D1): D427-32. https://doi.org/10.1093/nar/gky995.

67. Lu S, Wang J, Chitsaz F, Derbyshire MK, Geer RC, Gonzales NR, et al. CDD/ SPARCLE: the conserved domain database in 2020. Nucleic Acids Res. 2020; 48(D1):D265-8. https://doi.org/10.1093/nar/gkz991.

68. Letunic I, Doerks T, Bork P. SMART: recent updates, new developments and status in 2015. Nucleic Acids Res. 2015;43(Database issue):D257-60. https:// doi.org/10.1093/nar/gku949.

69. Gasteiger E, Hoogland C, Gattiker A, Wilkins MR, Appel RD, Bairoch A: Protein identification and analysis tools on the ExPASy server. In: The proteomics protocols handbook. Springer; 2005: 571-607.

70. Horton P, Park KJ, Obayashi T, Fujita N, Harada H, Adams-Collier CJ, et al. WoLF PSORT: protein localization predictor. Nucleic Acids Res. 2007;35(Web Server issue):W585-7.

71. Gu Z, Gu L, Eils R, Schlesner M, Brors B. Circlize implements and enhances circular visualization in R. Bioinformatics. 2014;30(19):2811-2. https://doi. org/10.1093/bioinformatics/btu393.

72. Wang Y, Tang H, Debarry JD, Tan X, Li J, Wang X, et al. MCScanX: a toolkit for detection and evolutionary analysis of gene synteny and collinearity. Nucleic Acids Res. 2012;40(7):e49. https://doi.org/10.1093/nar/gkr1293.

73. Zhu Y, Wu N, Song W, Yin G, Qin Y, Yan Y, et al. Soybean (Glycine max) expansin gene superfamily origins: segmental and tandem duplication events followed by divergent selection among subfamilies. BMC Plant Biol. 2014;14(1):93. https://doi.org/10.1186/1471-2229-14-93.

74. Goodstein DM, Shu S, Howson R, Neupane R, Hayes RD, Fazo J, et al. Phytozome: a comparative platform for green plant genomics. Nucleic Acids Res. 2012;40(Database issue):D1178-86. https://doi.org/10.1093/nar/ gkr944.

75. Kumar S, Stecher G, Suleski M, Hedges SB. TimeTree: a resource for timelines, timetrees, and divergence times. Mol Biol Evol. 2017:34(7):1812-9. https://doi.org/10.1093/molbev/msx116.

76. Wang D, Zhang Y, Zhang Z, Zhu J, Yu J. KaKs_Calculator 2.0: a toolkit incorporating gamma-series methods and sliding window strategies. Genomics, proteomics \& bioinformatics. 2010;8(1):77-80. https://doi.org/10.1 016/S1672-0229(10)60008-3.

77. Kumar S, Stecher G, Li M, Knyaz C, Tamura K. MEGA X: molecular evolutionary genetics analysis across computing platforms. Mol Biol Evol. 2018;35(6):1547-9. https://doi.org/10.1093/molbev/msy096.

78. Darriba D, Taboada GL, Doallo R, Posada D. ProtTest 3: fast selection of bestfit models of protein evolution. Bioinformatics. 2011;27(8):1164-5. https:// doi.org/10.1093/bioinformatics/btr088.

79. Hu B, Jin J, Guo AY, Zhang H, Luo J, Gao G. GSDS 2.0: an upgraded gene feature visualization server. Bioinformatics. 2015;31(8):1296-7. https://doi. org/10.1093/bioinformatics/btu817.

80. Lescot $M$, Déhais $P$, Thijs $G$, Marchal $K$, Moreau $Y$, Van de Peer $Y$, et al. PlantCARE, a database of plant cis-acting regulatory elements and a portal to tools for in silico analysis of promoter sequences. Nucleic Acids Res. 2002;30(1):325-7. https://doi.org/10.1093/nar/30.1.325.

81. Kolde R: Pheatmap: pretty heatmaps. R package version 2012, 1(2).

\section{Publisher's Note}

Springer Nature remains neutral with regard to jurisdictional claims in published maps and institutional affiliations.

\section{Ready to submit your research? Choose BMC and benefit from:}

- fast, convenient online submission

- thorough peer review by experienced researchers in your field

- rapid publication on acceptance

- support for research data, including large and complex data types

- gold Open Access which fosters wider collaboration and increased citations

- maximum visibility for your research: over $100 \mathrm{M}$ website views per year

At BMC, research is always in progress.

Learn more biomedcentral.com/submissions 